\title{
Modeling of Isoterm Phosphate Adsorption in Laundry Wastewater Using Anion Resin
}

\author{
Aussie Amalia ${ }^{1}$, Pritho Ajeng Maharani, Euis Nurul Hidayah, Raden Kokoh Haryo Putro \\ Departement of Environmental Engineering \\ Universitas Pembangunan Nasional "Veteran" Jawa Timur \\ Surabaya, Indonesia \\ 1euisnh@gmail.com
}

\begin{abstract}
The excess content of phosphate in laundry wastewater can cause eutrophication. Ion exchange is a method that has been widely used to remove pollutants in wastewater. The study of ion exchange equilibrium is generally carried out by means of adsorption isotherms modelling. The use of adsorption isotherms to model ion exchange systems involves that it is interpreted as a sorption process. The performance of an adsorbent can be studied by adsorption isotherm data which can be obtained by the experimental test in the laboratory. Modeling of adsorption isotherm data is a fundamental way to predict and compare adsorption performance, which is needed for the optimization of the adsorption mechanism pathways, the expression of the adsorbent capacity, and effective design of the adsorption system. This research applied three isotherm models namely Langmuir, Freundlich, and Dubinin-Radushkevich to determine and compare the isotherm models that suits best to remove phosphate on laundry waste using Lewatit MonoPlus MP $500 \mathrm{OH}$ anion resin. The best fitted for phosphate removal using Lewatit MonoPlus MP $500 \mathrm{OH}$ was using the Freundlich isotherm model with $5 \mathrm{ml} /$ minute for the best flow rate and 166 $\mathrm{cm}^{3}$ anion resin volume.
\end{abstract}

Keywords-Phospate; adsorption; ion exchange; anion resin; adsorption isotherm data

\section{INTRODUCTION}

Laundry wastewater that contain of phosphate causes environmental problem, one of the problems is eutrophication [1]. Ion exchange is a method that has been widely used to remove pollutants in wastewater. Removal phosphate can be achieved effectively using ion exchange resins. It can be able to improve $\mathrm{pH}$ in the solution and the ion exchange resins can be regenerated thus has a long-term use period [2]. Anion exchange resins effectively reduce anions pollutant in water using ion exchange adsorption methods [3].

Modeling adsorption isotherm is generally implemented for ion exchange equilibrium studies. Sorption reaction is theories in chemistry-physic that can be used to model ion exchange systems [2]. Basically, modeling adsorption isotherms can compare and predict the adsorption reactions that occur. The result from modeling adsorption isotherms can be used for optimization of adsorption reactions, calculating adsorption capacity and effective design of adsorption systems [4].
According to the research conducted by Foo [5], it can be concluded that the commonly used in the modeling of adsorption isotherm systems are Freundlich, Langmuir, Redlich-Peterson, Dubinin-Radushkevich, and Temkin. Chen [6] reported that the Langmuir model has a relatively high correlation coefficient $\left(\mathrm{r}^{2}\right)$ of 0.999 in the phosphate removal in wastewater by using $\mathrm{Fe}(\mathrm{III})$-coordinated aminofunctionalized mesoporous silica materials as adsorbent. Furthermore, the Freundlich model had better adsorption coefficient than Langmuir model in Rhodamine B adsorption on activated wood of Linggua wood with $\mathrm{r}^{2}=0.798$ [7]. The Dubinin-Radushkevich model was applied by Moawed [8] to remove aniline blue and crystal violet from laundry wastewater using iodo polyurethane, the result showed that the crystal violet had $\mathrm{r}^{2}=0.9918$ and $\mathrm{r}^{2}=0.947$ for aniline blue.

This research was conducted to apply the isotherm models i.e. Langmuir, Freundlich, and Dubinin-Radushkevich to determine and compare the isotherm models that are most suitable for phosphate adsorption on laundry waste using anion resin. Moreover, $\mathrm{r}^{2}$ and standard error (S.E.) for each parameter were used to evaluate the data. Data retrieval was accomplished by performing tests using a simple adsorption column.

\section{RESEARCH METHODS}

\section{A. Research Material and Tools}

The research was conducted using adsorption column. The adsorption column was a glass cylindrical column which generally had a large ratio of length and diameter. The dimension of the column had internal diameter of $4.2 \mathrm{~cm}$ and length of $30 \mathrm{~cm}$. The ion exchange resin used in this research is a particle monodisperse copolymer stirena-divinylbenzene resin strong base anion type I (Lewatit MonoPlus MP500 OH, Germany). Monodisperse particles have high chemical and osmotic stability (Lanxess Product Information). Strong base anion resin has been shown to be effective in removing arsenic anions. Resin is expected to have strong affinity for phosphate anions, because phosphates such as arsenic are specifically adsorbed in iron oxide [9]. 


\section{B. Research Procedure}

Experiments were conducted with inserted the resin into the column and maintained its position during the operation by installing glass fibers at the base of the column. Adsorption was carried out by flowing the waste that treated according to the predetermined discharge, i.e. $5 \mathrm{~mL} / \mathrm{min}, 10 \mathrm{~mL} / \mathrm{min}$, and 15 $\mathrm{mL} / \mathrm{min}$ through resin media. The volume of resin used were $166 \mathrm{~cm}^{3}, 194 \mathrm{~cm}^{3}$, and $235 \mathrm{~cm}^{3}$. The research was conducted with downflow system.

During the process, ion exchange occurs in resin with ions in laundry wastewater. The part of the bed that contacts first with waste will reach equilibrium first. When the resin has reached equilibrium, the following parts of the bed will be filled with waste ions. Therefore, the process in the adsorption column is a process that depends on time and distance. If the parts of the bed are saturated, the adsorbate concentration at the bed output will increase. Whether the resin is completely saturated, the release process will occur. The release of substances that have been adsorbed makes the pollutant concentration in the influent has the same concentration on the influent. Thus, the resin has lost the ability to conduct ion exchange.

\section{RESULT AND DISCUSSION}

\section{A. Effect of Flow rate On Phosphate Removal}

Flow rate affects the process of phosphate removal [10]. The Fig.1. explained the variation of waste flow rate had a similarity in the decrease of phosphate concentration. Each flow rate variation showed the percent removal that got bigger until the peak and showed the decline after. Percent removal around 91 to $99.9 \%$ on each resin volume variation. At 5 $\mathrm{mL} / \mathrm{min}$ flow rate, it took a longer processing time compared to $10 \mathrm{~mL} / \mathrm{min}$ flow rate. Percent removal at $5 \mathrm{~mL} / \mathrm{min}$ flow rate continued to increase until reached its peak. This occurred in the span of 15 to 60 minutes and decreased by the time.

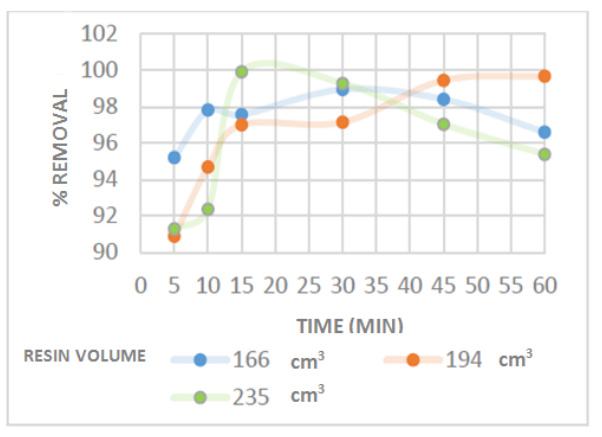

Fig. 1. Correlation of sampling time with percent removal in various resin volume at flow rate of $5 \mathrm{~mL} / \mathrm{min}$.

According to Fig. 2., flow rate of $10 \mathrm{~mL} / \mathrm{min}$ showed a longer saturation point than flow rate of $15 \mathrm{~mL} / \mathrm{min}$. Percent removal around 92 to $98 \%$ on each resin volume variation. Percent removal at $10 \mathrm{ml} / \mathrm{min}$ flow rate continued to increase until reached its peak in a faster time span compared to a flow rate of $5 \mathrm{~mL} / \mathrm{min}$ which occurred in 10 to 15 minutes. Furthermore, percent removal decreased by the time. This showed that the greater flow rate of removing phosphate in wastewater is not favorable [10].

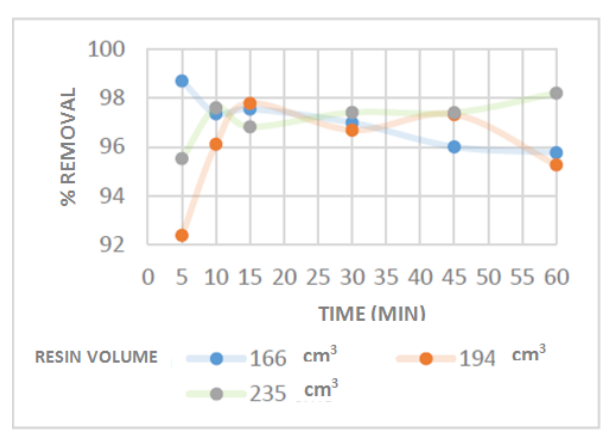

Fig. 2. Correlation of sampling time with percent removal in various resin volume at flow rate of $10 \mathrm{~mL} / \mathrm{min}$.

Based on Fig. 3., the percent removal of phosphate at 15 $\mathrm{mL} / \mathrm{min}$ around 70 to $96 \%$ on each resin volume variation. In the resin volume variation of $235 \mathrm{~cm}^{3}$, the percent removal increased at 15 minute of sampling time from $91 \%$ to $96 \%$ and decreased after its reached the highest peak of removal. However, the resin volume variations in $166 \mathrm{~cm}^{3}$ and $194 \mathrm{~cm}^{3}$ resulted that the percent removal of phosphate decreased without experiencing an increase, due to a short mass transfer zone. Based on study conducted by Fajrianti et al [11] shorter mass transfer zone or faster processing time causes the resin to saturate faster. The condition of saturated anion resin can be seen when percent removal decreased and effluent concentration increased near the initial concentration, so the ion exchange process for phosphate ions did not processed well.

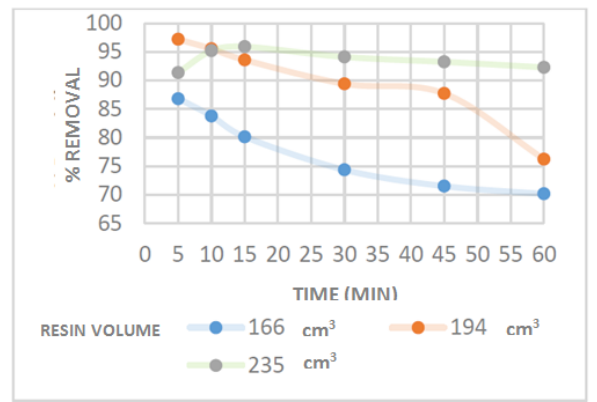

Fig. 3. Correlation of sampling time with percent removal in various resin volume at flow rate of $15 \mathrm{~mL} / \mathrm{min}$

According From the research it can be concluded that the phosphate removal was lower at a high flow rate compared to low flow rate. This is due to the rapid contact between the resin and the wastewater, therefore the possibility of phosphate ions being absorbed by the resin is very small. When its compared with a small flow rate, the contact between resin and waste lasts longer, thus the possibility of phosphate ions to be absorbed is greater.

Whether the $\mathrm{OH}$-ion exchange present in the resin is saturated with phosphate ions, it causes many phosphate ions to pass, according to the ion exchange reaction as follows:

$$
3 \mathrm{R}_{-}-\mathrm{OH}^{-}+\mathrm{H}_{3} \mathrm{PO}_{4} \rightarrow \mathrm{R}_{-} \mathrm{PO}_{4}{ }^{3-}+3 \mathrm{H}_{2} \mathrm{O}
$$


$\mathrm{PO}_{4}{ }^{3-}$ ions will replace $\mathrm{OH}^{-}$ions in resin through to all of $\mathrm{OH}^{-}$ ions are replaced by $\mathrm{PO}_{4}{ }^{3-}$ ions thus the ion exchange stops. The greater the flow rate flow rate flowing into the column, the smaller the percentage of ion removal. That happens because the greater the flow rate, the shorter the contact time in the column. Moreover, larger flow rate causes the $\mathrm{PO}_{4}{ }^{3-}$ ions to entering the column is increasing therefore the percentage of removal is decreasing.

\section{B. Effect of Resin Volume on Phosphate removal}

The volume of anion resin in the adsorption column influences phosphate removal. Based on Fig. 4., the average percent removal was between 70 to $99 \%$. The figure explained the resin volume of $166 \mathrm{~cm}^{3}$ with a flow rate of $5 \mathrm{~mL} / \mathrm{min}$ and $10 \mathrm{~mL} / \mathrm{min}$ percent removal was more stable with a result of the phosphate removal content around 95 to $99 \%$. On the other hand, result of $15 \mathrm{~mL} / \mathrm{min}$ flow rate was decreased at each sampling time. The result occured due to a small resin volume and a large flow rate, thus the effectiveness of resin will decrease faster [12].

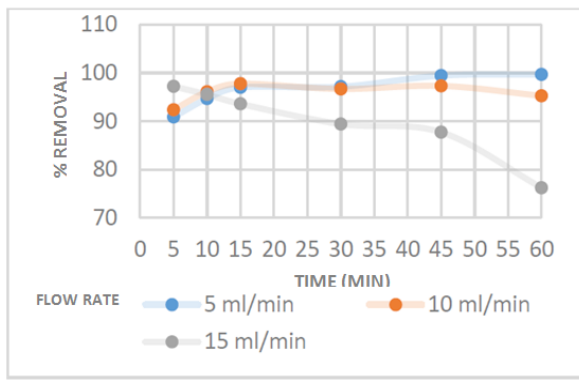

Fig. 4. Correlation of sampling time with percent removal in various flow rate on resin volume of $166 \mathrm{~cm}^{3}$

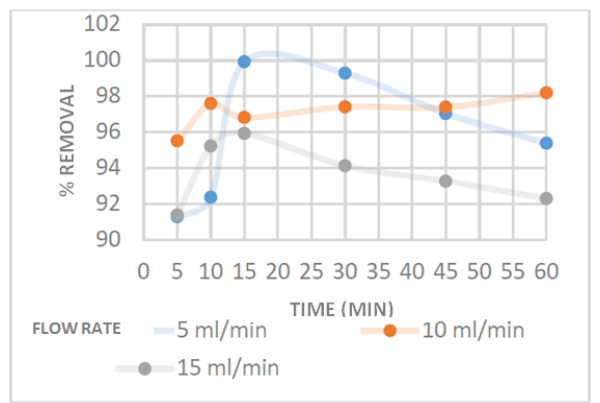

Fig. 5. Correlation of sampling time with percent removal in various flow rate on resin volume of $194 \mathrm{~cm}^{3}$

According to Fig. 5., the average percent removal of phosphate was around 75 to $99 \%$. The figure explained the resin volume of $194 \mathrm{~cm}^{3}$ with a flow rate of $5 \mathrm{~mL} / \mathrm{min}$ and 10 $\mathrm{mL} / \mathrm{min}$ showed a stable value of percent removal by resulting removal of phosphate values around 90 to $99 \%$. On the other hand, result of $15 \mathrm{~mL} / \mathrm{min}$ flow rate was decreased at each sampling time.

Based on Fig. 6., the figure explained that at 5 and 10 $\mathrm{mL} / \mathrm{min}$ flow rate with the amount of resin less than $235 \mathrm{~cm}^{3}$, phosphate can be removed with a percentage removal around 90 to $99 \%$ and the results were more stable. Whereas if the process that occurred at $15 \mathrm{~mL} / \mathrm{min}$ flow rate or greater, a greater amount of resin is needed otherwise the resin will saturate faster. The greater volume of resin in the adsorption column causes the amount of phosphate excreted to be bigger and longer to saturate. This is in accordance with previous studies that the greater the amount of resin used, the number of waste ions that absorbed is greater. Besides that, reference to Nur et al. [12] has the result that the greater amount of resin used, the efficiency of phosphate removal in wastewater is greater. This is due to the increase in the number of active sites available for the adsorption process.

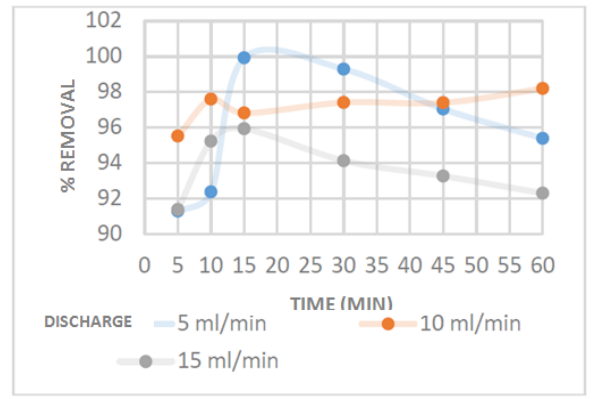

Fig. 6. Correlation of sampling time with percent removal in various flow rate on resin volume of $235 \mathrm{~cm}^{3}$

\section{Adsorption Isotherm Modeling}

An isotherm model that is fitted for the phosphate removal process in laundry wastewater can be determined by considering at $r^{2}$ which is closest to one. The correlation coefficient $\left(\mathrm{r}^{2}\right)$ can be calculated by (1):

$$
\mathrm{r}^{2}=\frac{\sum\left(\mathrm{q}_{\mathrm{m}}-\overline{\mathrm{q}_{\mathrm{e}}}\right)^{2}}{\sum\left(\mathrm{q}_{\mathrm{m}}-\overline{\mathrm{q}_{\mathrm{e}}}\right)^{2}+\sum\left(\mathrm{q}_{\mathrm{m}}-\overline{\mathrm{q}_{\mathrm{e}}}\right)^{2}}
$$

Where: $\mathrm{q}_{\mathrm{m}}=$ constant of isotherm model

$$
\begin{aligned}
& \mathrm{q}_{\mathrm{e}}=\text { the equilibrium capacity obtained from } \\
& \text { experimental data } \\
& \overline{\mathrm{q}_{\mathrm{e}}}=\text { the average of } \mathrm{q}_{\mathrm{e}} .
\end{aligned}
$$

Langmuir adsorption isotherm defines that the maximum adsorption capacity occurs due to the presence of a single adsorbate monolayer on the surface of the adsorbent and the entire site surface is homogeneous because each active site can adsorb merely one molecule of adsorbate [13]. Lagmuir isotherm pattern is a strong chemical bond [14]. Langmuir explained that on the surface of the adsorbent there are particular active sites that are proportional to its surface area. The application of Langmuir isotherm assumes that: a) adsorption is solely in the monomolecular, b) localized adsorption, and c) sorption heat does not depend on the surface layer. Langmuir adsorption isotherm can be known by the nonlinear formula described in (2) and the linear formula can be expressed in (3-6):

$$
\begin{aligned}
& q_{e}=q_{e} \cdot K_{L} \frac{C_{e}}{1+K_{L} \cdot C_{e}} \\
& \frac{C_{e}}{q_{e}}=\frac{1}{q_{m} \cdot K_{L}}+\frac{C_{e}}{q_{m}}
\end{aligned}
$$




$$
\begin{aligned}
& \frac{1}{q_{e}}=\left[\frac{1}{q_{m} \cdot K_{L}}\right] \cdot \frac{1}{C_{e}}+\frac{1}{q_{m}} \\
& q_{e}=q_{m}-\left[\frac{1}{K_{L}}\right] \cdot \frac{q_{e}}{C_{e}} \\
& \frac{q_{e}}{C_{e}}=K_{L} \cdot q_{m}+K_{L} \cdot Q_{e}
\end{aligned}
$$

where $\mathrm{Ce}=$ concentration of phosphate solution at equilibrium (mg P/L)

$\mathrm{qe}=$ corresponding adsorption capacity $(\mathrm{mg} \mathrm{P} / \mathrm{g})$

$\mathrm{qm}=$ constant of isotherm model $(\mathrm{mg} \mathrm{P} / \mathrm{g})$

$\mathrm{KL}=$ constant of net enthalpy of adsorption $(\mathrm{L} / \mathrm{mg})$

TABLE I. ADSORPTION ISOTHERM PARAMETERS OF LANGMUIR, FREUNDLICH AND DUBININ-RADUSHKEVICH

\begin{tabular}{|c|c|c|c|c|}
\hline \multirow{2}{*}{ Model } & \multirow{2}{*}{ Parameter } & \multicolumn{3}{|c|}{ Resin Volume $\left(\mathbf{c m}^{3}\right)$} \\
\cline { 3 - 5 } & & $\mathbf{1 6 6}$ & $\mathbf{1 9 4}$ & $\mathbf{2 3 5}$ \\
\hline \multirow{4}{*}{ Langmuir } & $\mathrm{q}_{\mathrm{m}}(\mathrm{mg} \mathrm{P} / \mathrm{g})$ & 344.827 & 322.581 & 263.158 \\
\cline { 2 - 5 } & $\mathrm{K}_{\mathrm{L}}(\mathrm{l} / \mathrm{mg} \mathrm{P})$ & -3.625 & -44.286 & -19.000 \\
\cline { 2 - 5 } & $\mathrm{r}^{2}$ & 0.499 & 0.303 & 0.499 \\
\hline \multirow{4}{*}{ Freundlich } & $\mathrm{K}_{\mathrm{f}}$ & 446.527 & 338.323 & 282.958 \\
\cline { 2 - 5 } & $\mathrm{N}$ & -9.960 & -31.060 & -26.880 \\
\cline { 2 - 5 } & $\mathrm{r}^{2}$ & 0.879 & 0.734 & 0.874 \\
\hline \multirow{3}{*}{ Dubinin-Radushkevich } & $\mathrm{Q}_{\mathrm{s}}(\mathrm{mg} \mathrm{P} / \mathrm{g})$ & 363.181 & 323.694 & 267.736 \\
\cline { 2 - 5 } & $\mathrm{K}_{\mathrm{D}}\left(\mathrm{mol}^{2} / \mathrm{kJ}^{2}\right)$ & 0.073 & 0.006 & 0.001 \\
\cline { 2 - 5 } & $\mathrm{r}^{2}$ & 0.344 & 0.264 & 0.378 \\
\hline
\end{tabular}

Table 1 shows the value of isotherm parameters for each volume resin. In Table 1 , the correlation coefficient $\left(r^{2}\right)$ in Langmuir model $\left(0.499,0.303\right.$, and 0.499 for $166 \mathrm{~cm}^{3}, 194$ $\mathrm{cm}^{3}$, and $235 \mathrm{~cm}^{3}$ of volume resin) had small values and all Langmuir adsorption constants were negative (-) number. In the variation of $166 \mathrm{~cm}^{3}$ resin volume had the highest maximum adsorption capacity about $344,8276 \mathrm{mg} / \mathrm{gram}$. Adsorption capacity can be used to determine the volume of reactor needed for the adsorption process. The greater the adsorption capacity, the greater the reactor volume.

The Freundlich's isotherm model can be applied to multilayer and affinities over heterogeneous surface, on the basis of binding energy at each site, where the adsorption process in each layer follows the Langmuir isotherm [13]. Freundlich adsorption isotherms can be known by the nonlinear formula described in (7) and the linear formula described in (8):

$$
\begin{aligned}
& \mathrm{q}_{\mathrm{e}}=\mathrm{K}_{\mathrm{F}} \cdot \mathrm{C}_{\mathrm{e}}{ }^{1 / \mathrm{n}} \\
& \ln \mathrm{q}_{\mathrm{e}}=\ln \mathrm{K}_{\mathrm{F}}+\frac{1}{\mathrm{n}} \cdot \ln \mathrm{C}_{\mathrm{e}}
\end{aligned}
$$

where $\mathrm{KF}=$ constants of the adsorption capacity

$$
\mathrm{n}=\text { constant of the adsorption intensity }
$$

As shown in Table 1, the correlation coefficient $\left(\mathrm{r}^{2}\right)$ in Freundlich model $\left(0.879,0.734\right.$, and 0.874 for $166 \mathrm{~cm}^{3}, 194$ $\mathrm{cm}^{3}$, and $235 \mathrm{~cm}^{3}$ of volume resin) had greater value compared to Langmuir isotherm. The minus value (-) obtained at the adsorption intensity of ( $\mathrm{n}$ ) is the effect of the small bond energy between the adsorbate and the active site [14].

Dubinin-Radushkevich formulated an isotherm model based on the pore filling mechanism. This is generally applied to express the adsorption process occurs on homogeneous and heterogeneous surfaces [6]. Dubinin-Radushkevich adsorption isotherm can be known by the non-linear formula described in $(9,10)$ and the linear formula described in $(11)$ :

$$
\begin{aligned}
& \mathrm{Q}_{\mathrm{e}}=\mathrm{q}_{\mathrm{s}} \cdot \exp \cdot\left(-\mathrm{K}_{\mathrm{DR}} \cdot \varepsilon^{2}\right) \\
& \varepsilon=\mathrm{RT} \cdot \ln \left(1+\frac{1}{\mathrm{C}_{\mathrm{e}}}\right) \\
& \operatorname{lnq}_{\mathrm{e}}=\ln \mathrm{q}_{\mathrm{s}}-\mathrm{K}_{\mathrm{DR}} \cdot \varepsilon^{2}
\end{aligned}
$$

where qs = constant in the Dubinin-Radushkevich isotherm model which are related to adsorption capacity $(\mathrm{mg} \mathrm{P} / \mathrm{g})$

$\mathrm{KDR}=$ constant in related to the mean free energy of

adsorption (mol2/kJ2)

$\mathrm{R}=$ = the gas constant $(\mathrm{J} / \mathrm{mol} \mathrm{K}$

$\mathrm{T}=$ the absolute temperature $(\mathrm{K})$

Based on Table 1, it is known that the correlation coefficient $\left(r^{2}\right)$ in Dubinin-Radushkevich model (0.344, 0.264, and 0.378 for $166 \mathrm{~cm}^{3}, 194 \mathrm{~cm}^{3}$, and $235 \mathrm{~cm}^{3}$ of volume resin) had the smallest value compared to Langmuir and Freundlich isotherms. According to the result, the highest value of saturation capacity was obtained by using variations of volume resin of $166 \mathrm{~cm}^{3}$ with $363,1805 \mathrm{mg} /$ gram.

Fig. 7-9 shows the Langmuir, Freundlich, and DubininRadushkevich adsorption isotherms by linear analysis. Correlation coefficient $\left(\mathrm{r}^{2}\right)$ generated from each equation has different values due to different assumptions about the adsorption mechanism that occurs between adsorbent and adsorbate on each equation of isotherm [11]. The correlation coefficient $\left(r^{2}\right)$ which is closest to one will determine the most suitable model as a model for phosphate adsorption in laundry wastewater using anion resin. Table 1 showed that the biggest $\mathrm{r}^{2}$ value was Freundlich Isoterm Model $\left(\mathrm{r}^{2}>0.7341\right)$, while the Langmuir and Dubinin-Radushkevich Isoterm Models had low $r^{2}$ value $\left(r^{2}>0.303\right.$ and $\left.r^{2}>0.2637\right)$.

In table 1 , the largest $r^{2}$ value were resulted from the freundlich model on $166 \mathrm{~cm}^{2}$ anion resin volume in each variation flow rate $\left(r^{2}=0.8788\right)$. The result suggested that the freundlich isotherm can describe a better adsorption mechanism compared to other isotherm equations. Based on this, the equation to be chosen as the adsorption model is the freundlich isotherm model. With the selection of the freundlich isotherm as the adsorption model, the phosphate adsorption process in laundry wastewater occurs multilayer, 
which will form more from one layer on the surface of the adsorbent.

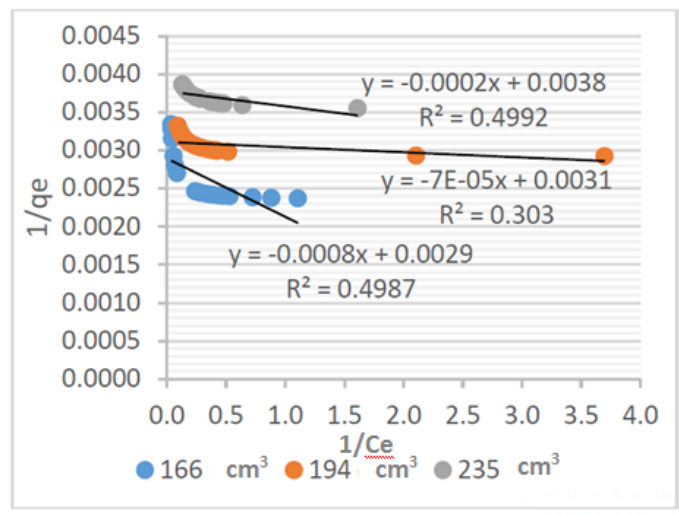

Fig.7. Linear fitting plot of Langmuir adsorption isotherm

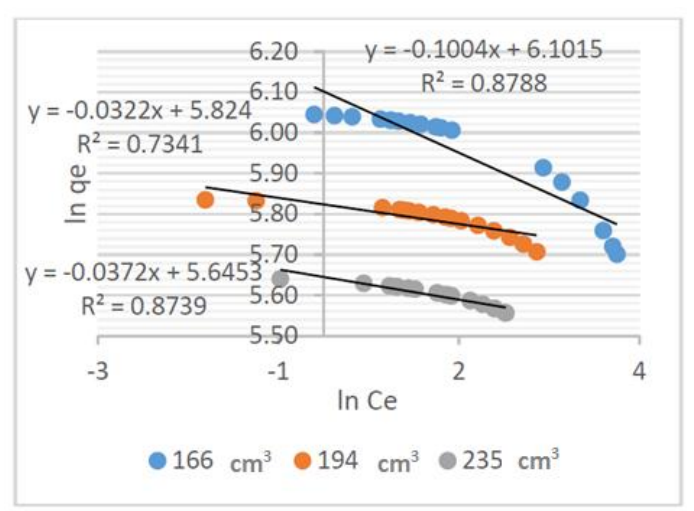

Fig. 8. Linear fitting plot of Freundlich adsorption isotherm

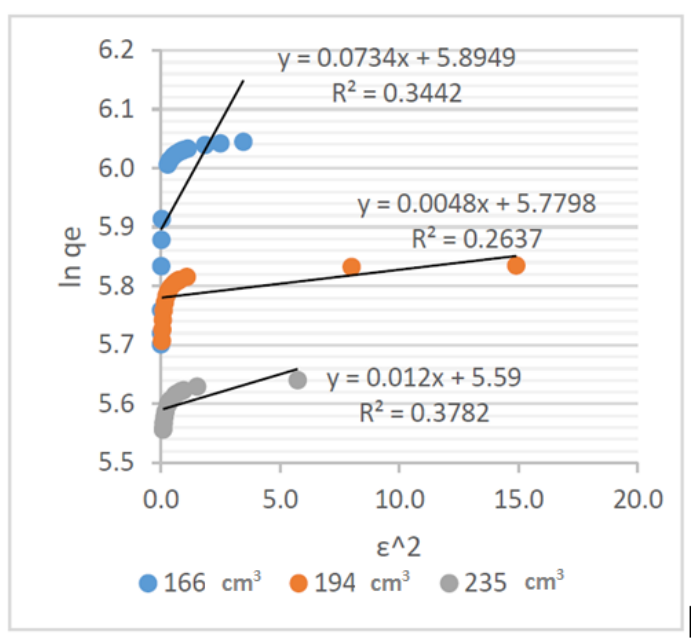

Fig. 9. Linear fitting plot of Dubinin-Raduhkevich adsorption isotherm

Freundlich's isotherm model assumes that there are more than one-layer surface (multilayer) where the adsorption process in each layer follows the Langmuir isotherm and the side is heterogeneous, based on the difference in binding energy on each side of the adsorbent [13]. However, according to Dron's [2] study that all research carried out on ionicshaped materials and similar adsorbents with anionic resin should not have an impact on surface heterogeneity. Determination of the maximum adsorption power of anion resin in the phosphate ion adsorption process in the Freundlich model is calculated using the Langmuir isotherm adsorption equation [14]. The calculation results showed that the maximum adsorption capacity of the Lewatit MonoPlus MP500 OH of $166 \mathrm{~cm}^{3}$ resin volume in flow rate $(5,10$, and $15 \mathrm{~mL} / \mathrm{min}$ ) was $344.828 \mathrm{mg} / \mathrm{gram}$. This means that every gram of weight of Lewatit MonoPlus MP500 OH anion resin has the ability to remove about $344.828 \mathrm{mg}$ of pollutant weight.

\section{One Way ANOVA Test}

One Way ANOVA is used for analyze one-way ANOVA model, where the response data structure is written in a column (stacked) and another column as a sub-script of each treatment. One Way ANOVA do the similarity test on the mean of several population classified according to variables or factors. Each variable or factor has a level (treatment). The result of One Way ANOVA statistical analysis using Minitab 2017 software according to the variables in the study explained that The OneWay ANOVA output was obtained p-value $=0,000$. The output means that $\mathrm{p}$-value $>0.05$ then the result concluded that there is sufficient evidence to say that every treatment will not have same average Phosphate concentrations.

Based on the results of the One-Way ANOVA test defined the difference in the average concentration of phosphate after going through the treatment process. In treatment $1(\mathrm{Q}=5$ $\mathrm{mL} / \mathrm{min}$; volume $=166 \mathrm{~cm}^{3}$ ) showed the smallest average effluent phosphate concentration when compared to other treatments, this means that treatment 1 had efficiency optimal processing. On the other hand, in treatment $7(\mathrm{Q}=15 \mathrm{~mL} / \mathrm{min})$ showed the highest concentration of phosphate effluent when compared to other treatments, meaning that efficiency processing in treatment 7 is the least effective.

TABLE II. TUKEY TEST

\begin{tabular}{|c|c|c|}
\hline Treatment & Mean & Grouping \\
\hline $7\left(15 \mathrm{ml} . \mathrm{min} ; 166 \mathrm{~cm}^{2}\right)$ & 19.24 & A \\
\hline $8\left(15 \mathrm{ml} / \mathrm{min} ; 194 \mathrm{~cm}^{2}\right)$ & 8.7 & B \\
\hline $9\left(15 \mathrm{ml} / \mathrm{min} ; 235 \mathrm{~cm}^{2}\right)$ & 5.455 & BC \\
\hline $3\left(5 \mathrm{ml} / \mathrm{min} ; 194 \mathrm{~cm}^{2}\right)$ & 3.57 & BC \\
\hline $5\left(10 \mathrm{ml} / \mathrm{min} ; 194 \mathrm{~cm}^{2}\right)$ & 3.537 & BC \\
\hline $2\left(5 \mathrm{ml} / \mathrm{min} ; 194 \mathrm{~cm}^{2}\right)$ & 3.05 & BC \\
\hline $4\left(10 \mathrm{ml} / \mathrm{min} ; 166 \mathrm{~cm}^{2}\right)$ & 2.552 & BC \\
\hline $6\left(10 \mathrm{ml} / \mathrm{min} ; 235 \mathrm{~cm}^{2}\right)$ & 2.464 & BC \\
\hline $1\left(5 \mathrm{ml} / \mathrm{min} ; 166 \mathrm{~cm}^{2}\right)$ & 2.225 & C \\
\hline
\end{tabular}

Based on the Tukey Test that shown in Table 2, on treatments 1,7 , and 8 resulted significantly different effluent phosphate concentration, meaning that the process that carried out with a discharge of $5 \mathrm{~mL} / \mathrm{min}$ and $15 \mathrm{~mL} / \mathrm{min}$ had a significant difference in efficiency process. However, in 
treatments 2, 3, 4, 5, 6, and 9 showed the identical phosphate concentration effluent.

\section{CONCLUSION}

Based from the results of research and discussion conducted, then got the following conclusion:

1. The optimum discharge and volume of resin anion was at discharge of $5 \mathrm{~mL} / \mathrm{min}$ with variations in volume of 166 $\mathrm{cm}^{3}$ resin.

2. The higher of the flow rate flowing into the column then the percentage ion removal were getting smaller. The increasing flow rate causes the contact time in the column become shorter and makes the ions $\mathrm{PO}_{4}{ }^{3-}$ that goes into the column were abundant. High ions content resulted low removal percentage.

3. The amount of anion resin affects the removal efficiency of phosphate concentration in wastewater.

4. The fitted model for phosphate removal on laundry wastewater using anion resin was the Freundlich isotherm model with the linear equation $y=-0,1004 x+6,1015$ has a value of $\mathrm{r}^{2}=0.8788$, Freundlich coefficient $(\mathrm{Kf})=$ 446,527 and maximum adsorption capacity $344,8276 \mathrm{mg}$ / gram.

\section{REFERENCES}

[1] I. M. D. Andika, I. N. Simpen, K. G. D. Putra, "Adsorption and desorption of $\mathrm{Cr}$ (VI) in Batu Cadas Karangasem adsorben from craft waste using $\mathrm{NaOH}$ activation and $\mathrm{Fe}(\mathrm{OH}) 3$ ", Jurnal Kimia FMIPA Universitas Udayana, Bukit Jimbaran, Bali, ISSN 1907-9850, 2016.

[2] J. Dron, A. Dodi, "Comparison of adsorption equilibrium models for the study of $\mathrm{CL}-$, NO3- and SO42- removal from aqueous solutions by an anion exchange resin". J. of Hazard. Mater., 190 (2011) 300-307, June 2011.
[3] T. Setiadi," Treatment and supply water", Diktat Kuliah Tk-2206 Sistem Utilitas I, Institut Teknologi Bandung, 2007.

[4] G. Thompson, "The Treatment Of Pulp And Paper Mill Effluent: A Review”, Bioresource Technol., vol. 77, pp. 275 - 286, May 2001.

[5] K. Y. Foo \& B. H. Hameed, "Insights Into The Modeling Of Adsorption Isotherm Systems", Chem. Eng. J., vol. 156, pp. 2-10, January 2010

[6] X. Chen, "Modeling Of Experimental Adsorption Isotherm Data", Information, vol. 6, pp. 14-22, January 2015.

[7] S. H. Roring, "Rhodamin B Isotherm Adsorption in Lingua wood activated carbon", Jurnal MIPA UNSRAD Online, 2013.

[8] E. A. Moawed, "Synthesis And Characterization of Iodo Polyurethane Foam and Its Application in Removing Of Aniline Blue and Crystal Violet from Laundry Wastewater". J. of Taibah University for Sci., January 2014.

[9] P. Loganathan, S. Vigneswaran, J. Kandasamy, N.S. Bolan, "Critical Reviews", in Environmental Sci. and Technol. (in press), 2013.

[10] C. Lee, J. Jung, R. R. Pawar., M. Kim, Lalhmunsiama., S. Lee,”Arsenate and Phosphate Removal from Water Using Fesericite Composite Beads in Batch and Fixed-bed System".Journal of Industrial and Engineering Chemistry, vol. 47, pp. 375-383, 2017.

[11] H. Fajrianti, W. Oktiawan, I. W. Wardhana, "Effect of Immersion Time in $\mathrm{NaOH}$ Activator and Flow Rate Against Decreasing of Chrome Total $(\mathrm{Cr})$ and Zinc $(\mathrm{Zn})$ in Electroplating Industry wastewater by Using Active Charcoal from Banana Skin”. Jurnal Teknik Lingkungan, Vol 5, No 1, 2016

[12] T. Nur, M. A. H. Johir, P. Loganathan, T. Nguyen, S. Vigneswaran, J. Kandasamy, "Phosphate Removal from Water Using An Iron Oxide Impregnated Strong Base Anion Exchange Resin". J. of Industrial and Eng. Chem., vol. 20, pp. 1301-1307, January 2014.

[13] A. N. Muna, "Kinetics of Activated Carbon Adsorption from Banana Rods as Adsorbents for Absorption of Cr (VI) Metal Ions in Industrial Wastewater", 2011.

[14] M. Handayani, E. Sulistiono, "Langmuir and Freundlich Equations on Chrom (VI) Waste Absorption by Zeolites". Indonesian Institute of Sci. J., June 2009. 